Article

\title{
Setting and Implementing Standards for Management of Wild Tigers
}

\author{
M. K. S. Pasha ${ }^{1, *}$, Nigel Dudley ${ }^{2,3}{ }^{(1)}$, Sue Stolton ${ }^{2}{ }^{(0)}$, Michael Baltzer ${ }^{1}$, Barney Long ${ }^{4}$, \\ Sugoto Roy ${ }^{5}{ }^{(1)}$, Michael Belecky ${ }^{1}$, Rajesh Gopal ${ }^{6}$ and S. P. Yadav ${ }^{6}$ \\ 1 WWF Singapore, 354 Tanglin Road, Tanglin Block, Tanglin International Centre, Singapore 247672, \\ Singapore; mbaltzer@wwfnet.org (M.Ba.); mbelecky@wwf.sg (M.Be.) \\ 2 Equilibrium Research, 47 The Quays, Spike Island, Cumberland Road, Bristol BS1 6UQ, UK; \\ nigel@equilibriumresearch.com (N.D.); sue@equilibriumresearch.com (S.S.) \\ 3 School of Geography, Planning and Environmental Management, University of Queensland, Brisbane, \\ QLD 4072, Australia \\ 4 Global Wildlife Conservation, 500 N Capital of Texas Hwy Building 1, Suite 200, Austin, TX 78746, USA; \\ blong@globalwildlife.org \\ 5 International Union for Conservation of Nature, Global Species Programme, Rue Mauverney 28, 1196 Gland, \\ Switzerland; Sugoto.Roy@iucn.org \\ 6 Global Tiger Forum, 200, Jor Bagh Road, Third Floor (Near Jor Bagh Metro Station), New Delhi 110003, India; \\ rajeshgopal.sg.gtf@gmail.com (R.G.); spyadavifs@gmail.com (S.P.Y.) \\ * Correspondence: kpasha@wwf.sg
}

Received: 30 June 2018; Accepted: 27 July 2018; Published: 31 July 2018

check for updates

\begin{abstract}
Tiger numbers have collapsed so dramatically that conservationists are adopting a strategy of securing populations in priority conservation landscapes. This includes improving management effectiveness in these sites. The Conservation Assured I Tiger Standards (CA I TS) are designed to help ensure effectiveness and provide a benchmark against which to measure progress. CA I TS is a distillation of best practice and a roadmap to management effectiveness, linking management to expert-driven standards covering all aspects of management, including those which are tiger-specific (monitoring, maintenance of prey, control of poaching). Sites are audited against a set of standards and if met, are accredited as CA I TS Approved. We describe CA I TS in the context of tiger conservation, describe the evolution and philosophy of the system and consider its application across the tiger range, before drawing on lessons learned from 5 years of development. Important benefits include the independence of CA I TS from existing governmental or NGO institutions, the emphasis on regional governance and the existence of active support groups. Conversely, the participatory approach has slowed implementation. CA I TS remains more attractive to well managed sites than to sites that are struggling, although building capacity in the latter is its key aim. The close connections between people working on tiger conservation make some aspects of independent assessment challenging. Finally, if CA I TS is to succeed in its long term aims, it needs to go hand in hand with secure and adequate funding to increase management capacity in many tiger conservation areas.
\end{abstract}

Keywords: Tiger; conservation standards; protected area management; management effectiveness; accreditation; conservation assured

\section{Introduction}

Global tiger (Panthera tigris) population size has fallen by over 95\% since the turn of the 20th century-down from perhaps 100,000 to roughly 3900 individuals (Wolf and Ripple, 2017) [1]. Furthermore, tigers have lost over $93 \%$ of their historic range (Walston et al., 2010) [2]. There are now only 13 recognised Tiger Range Countries (TRCs: Bangladesh, Bhutan, Cambodia, China, India, 
Indonesia, Lao PDR, Malaysia, Myanmar, Nepal, Russia, Thailand, and Vietnam), of which only 10 still have wild tiger populations (WWF, 2015 [3], see Figure 1). Many other countries that formerly held tigers, such as South Korea and Kazakhstan, have lost their populations altogether. Tigers have been all but driven to extinction by poaching, illegal trade (Stoner and Pervushina, 2013) [4], habitat fragmentation, deforestation and diminishing prey (Damania et al., 2008) [5].

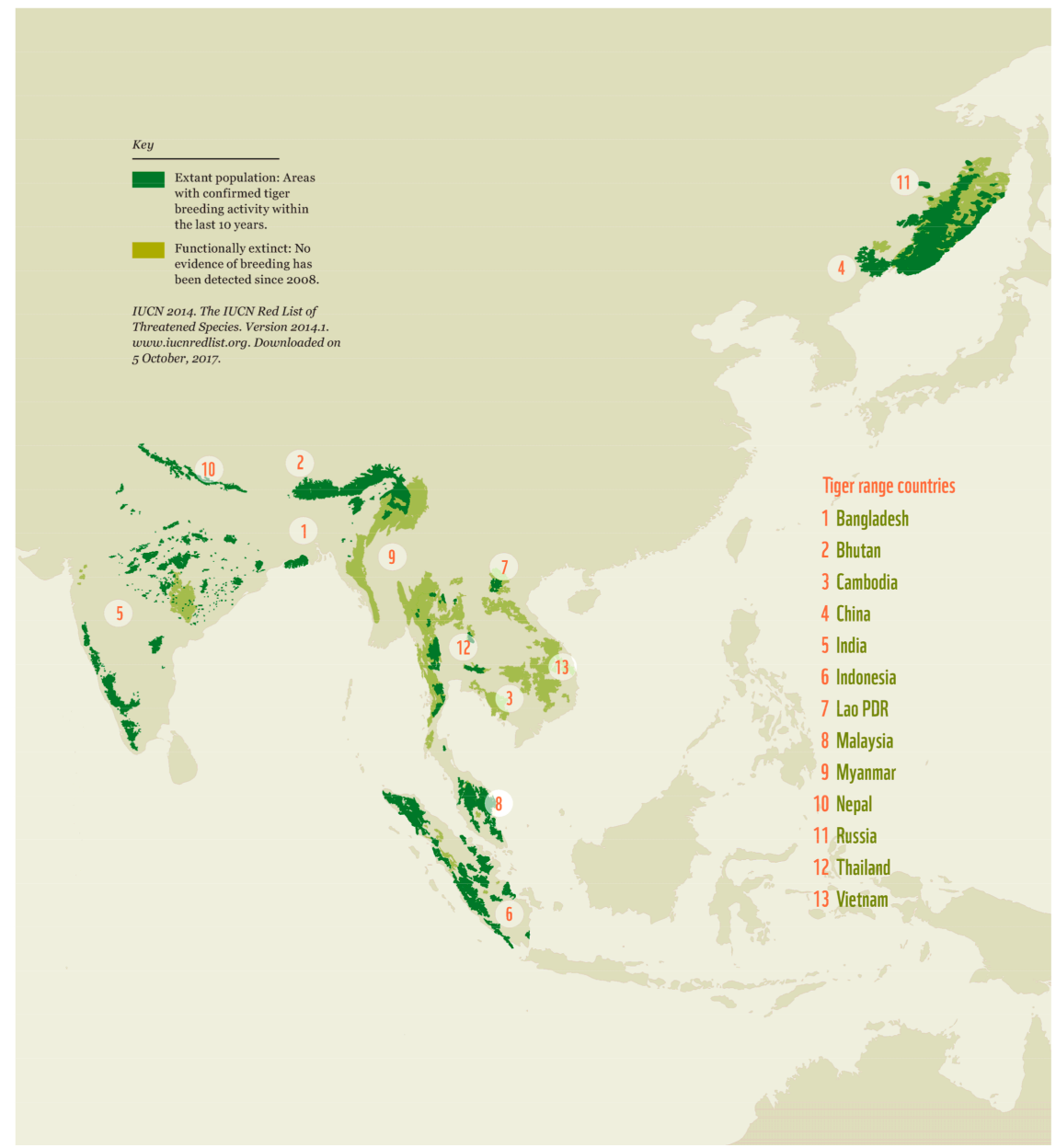

Figure 1. Distribution Range Wild Tigers.

In response to a serious threat of extinction of wild tigers, in 2010 the conservation community committed to doubling the global wild tiger population by 2022 (known as TX2) at a major 'tiger summit' in St. Petersburg (Global Tiger Initiative, 2010) [6]. This global goal was supported by all 13 TRCs and a global political infrastructure was established to coordinate and monitor action towards this goal. Many governments, donors and non-governmental organisations committed additional funds and personnel to focus on tiger conservation, such as German support for the Integrated Tiger Habitat Conservation Programme (Roy et al., 2016) [7], and there were high profile statements of support from global leaders.

Tigers require large areas of forest to survive. Historically, conservation strategies have focused on the designation of protected areas. There is clear evidence that site protection should remain the cornerstone of conservation for the vast majority of threatened amphibians, reptiles, birds and mammals. Quantitative analysis provides strong evidence that well-managed protected areas are an effective method of site protection (Geldmann et al., 2018) [8]. In the face of a worsening conservation status for tigers, an identified priority action is to secure stable tiger populations within identified protected areas, as a source of landscape-scale expansion (Walston et al., 2010) [2]. 
However, designation of protected areas alone is not enough. Global analysis has shown that many protected areas are currently not effectively managed (Leverington et al., 2010) [9], and the problem of 'paper parks' is well noted (e.g., Brun et al., 2015) [10]. Recent research confirms many management shortcomings in tiger conservation areas (Conservation Assured, 2018) [11-13].

Therefore, although the number of tiger conservation areas (TCAs) has increased over the past few years, a commensurate increase in tiger population will only occur if TCAs attain effective management. Concrete, measurable steps to improve management effectiveness in tiger reserves are a critical component of tiger conservation strategies. In turn, there is need for clear guidance on how best to manage tigers, address wider issues such as human-wildlife conflict, and develop agreed ways of verifying the effectiveness of tiger conservation.

In this paper, we discuss a set of verifiable management standards known as Conservation Assured I Tiger Standards (CAITS). We examine how these differ from existing management effectiveness evaluation (MEE) processes, the development and application of CA I TS, application to date, lessons learned, and the scope for widening the approach.

\section{Moving from Management Effectiveness to Management Standards}

Over the last 20 years, our understanding of what constitutes good management of protected areas has increased considerably. More than 40 management effectiveness (MEE) data collection tools have been developed. These have been based largely on principles from the IUCN World Commission for Protected Areas. Hockings et al. (2006) [14] describe the mechanisms and rationale for MEE, along with many of the methods used world-wide. By 2013, the date of the last global survey, the IUCN Protected Area Management Effectiveness database held over 10,000 records and 90 countries had met the Convention on Biological Diversity (CBD) 2010 target of carrying out MEE in at least 30 per cent of their protected areas (Coad et al., 2013) [15]. An MEE system has also been developed explicitly for tiger protected areas in India called the MEETR-Management Effective Evaluation for Tiger Reserves (Mathur et al., 2014) [16].

MEE tools identify when things are going wrong, but they do not necessarily provide concrete steps for improvement, nor do they set standards against which to measure results and document change. The CBD identified the need for such standards in its 2004 Programme of Work on Protected Areas (CBD, 2004) [17]. Standards can, among other things, define key terminology; determine which data, methods and approaches are most favourable; and specify monitoring needs and the reporting format. They provide clear guidance on minimum requirements for effective management. There is good evidence that standards improve adoption of best practices, learning, performance-based awards, and the quality of results (Polasky, 2015) [18]. Standards also help donors to assess if investments are used effectively (Ferraro and Patanayak, 2006; McCarthy, 2012) [19,20]; for both institutional and private donors (Bennett et al., 2015) [21].

MEE tools, although useful for evaluating management objectives, offer less in terms of measuring management against best practice. CA I TS was designed to fill this gap and to provide species-specific conservation standards to help drive and measure progress towards improved tiger conservation (Conservation Assured, 2018a) [12]. It does not replace existing MEE tools; indeed, the implementation of site-based MEE is one of the standards of management included within the broader aims of CA I TS.

\section{Methods}

CAITS was developed after an exhaustive literature review and stakeholders' consultation including protected area managers in TRCs and tiger experts from around the world. The approach drew from experience with establishing voluntary certification systems for natural resources such as food and timber, but went considerably further in terms of setting detailed standards for management. Standards were developed in accordance with the ISEAL Principles for Credible and Effective Sustainability Standards Systems (ISEAL, 2013) [22]. Workshops were conducted in India, Nepal, Bhutan and Malaysia, to draw up and refine the draft standards, which were field-tested and subject 
to further review. The system was designed to have applicability across all TRCs, covering varied geographical, cultural and ecological needs. The CA I TS standards are reviewed periodically as best practice evolves.

Governance (see Figure 2) begins with a broad CA I TS Partnership, which includes tiger and conservation management experts from around the world. An International Executive Committee ensures good governance and equivalence of implementation across TRCs. CA I TS functions through National Committees comprising government, NGO, experts and academic representatives, ideally embedded within an existing policy and institutional framework. The CAITS Council brings representatives from National Committees together to share experiences; and is represented on the International Executive Committee. The CA I TS management team ensures technical and financial viability and the CA I TS support group (a wide range of non-governmental and intergovernmental organizations) provides support to TRCs undertaking CA I TS.

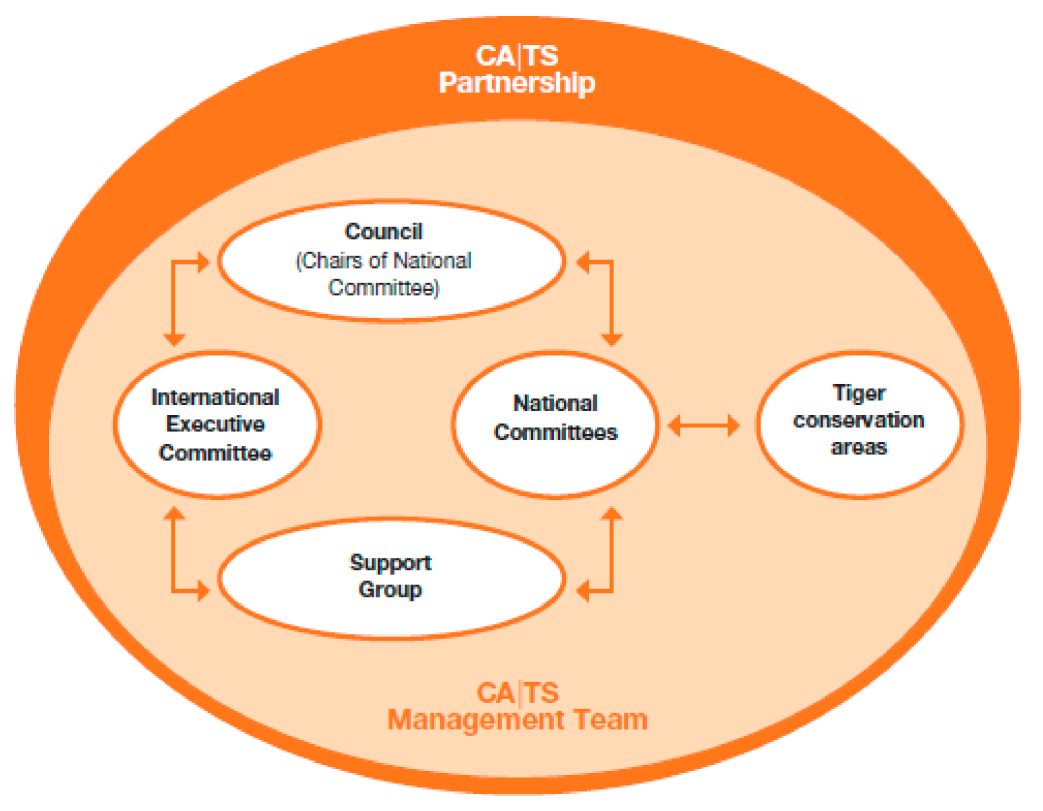

Figure 2. Conservation Assured I Tiger Standards (CA I TS) management structure.

CA ITS has a hierarchical structure; seven 'pillars' covering different management issues, 17 elements (see Figure 3), subdivided into standards, for which criteria have been laid down (management actions required and a list of actions taken). For each standard, four values have been provided for reporting on compliance: Standard exceeded, standard achieved, standard mainly achieved and standard not achieved.

Protected areas and other tiger conservation areas first become CA I TS Registered and then go through an accreditation process to judge whether they meet CAITS Approved status. CAITS Registration demonstrates commitment to achieve best practice and identifies gaps in current management, providing a strategy for managers and a clear indication of needs to donors and potential supporters. For some sites CA I TS Registration may initiate a several year process of management intervention and improvement to reach the CA I TS Approved status; in these cases, the standards and criteria can be used as a gap analysis and planning tool to identify management actions which need to be put into place to reach Approved status. 


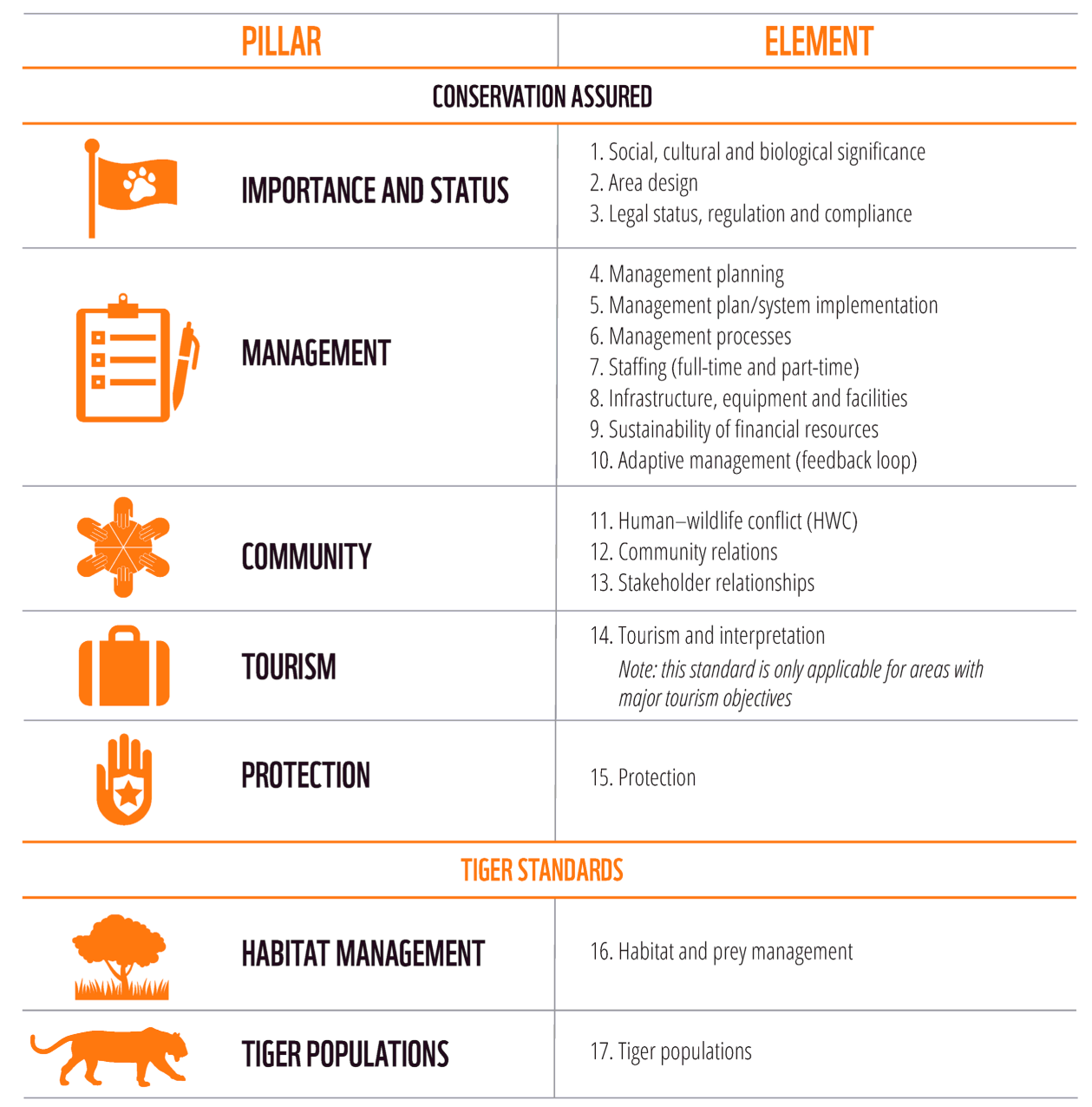

Figure 3. CA I TS pillars and elements.

The CA I TS assessment is an iterative process which starts with a manager's self-assessment of the site against the CA I TS standards and criteria. The assessment is then reviewed and refined by the National Committee. An independent reviewer also reviews the entire CA I TS process before a final decision on status is made. Once the national process is complete and the National Committee recommends that a site has reached CA I TS Approved status, the International Executive Committee provides a final check to ensure parity between countries. Training is provided for all those taking part in CA I TS to ensure effective and consistent application. Approval lasts for 3 years, when a streamlined review process takes place. If there are significant changes in management or circumstances the area may need to update and resubmit its dossier to the National Committee and International Executive Committee.

\section{Results}

Since its launch, CAITS has achieved broad-based support and obtained commitment to implement from all TRCs. Presently it is being implemented across 60 sites in seven TRCs (Bhutan, Bangladesh, China, India, Malaysia, Nepal and Russia), where National Committees have been established. Three sites have attained CA I TS Approved status (Chitwan National Park, Nepal, Sikhote-Alin Nature Reserve, Russia and Lansdowne Forest Division, India) and currently (as of June 2018) 18 dossiers are pending final approval. CA I TS has also been used for assessing the readiness of tiger reintroduction in Cambodia (Gray, et al., 2017) [23]. 
CA I TS can also measure progress in implementing international conventions, multilateral treaties, global initiatives and national conservation plans (Conservation Assured, 2014) [24]. CA I TS is partnered with IUCN's Green List of Protected and Conserved Areas, an initiative to identify and promote protected areas reaching excellent standards of management (IUCN 2013) [25]. It will help governments and their partners to meet the CBD's Strategic Plan for Biodiversity, particularly Targets 11, 12, (Strategic Goal C: To improve the status of biodiversity by safeguarding ecosystems, species and genetic diversity); 14 (Strategic Goal D: Enhance the benefits to all from biodiversity and ecosystem services) and 19 (Strategic Goal E: Enhance implementation through participatory planning, knowledge management and capacity building). Within the Convention on International Trade in Endangered Species of Wild Fauna and Flora (CITES), CA I TS helps state parties to fulfil commitments under 16.68(b) to 'provide information on incidents of poaching' (CITES, 2016) [26]. It also helps to evaluate anti-poaching plans, to fulfil the 'Zero Poaching Initiative' approach, formally endorsed in the most recent CITES Conference of Parties (Decision 17.225).

\section{Experience with Existing CA I TS Approved Sites}

As noted above, three sites have so far been awarded the CA I TS Approved status. Each site is unique and this variety has helped the CA I TS Partnership learn more about the CA I TS approach. A summary of the assessment and findings is given for each site below.

Nepal: Nepal has been actively engaged in the development of CA I TS from the beginning and nominated the first site to be CA I TS Registered. The assessment of Chitwan National Park (CNP) for CA I TS was conducted in 2013/2014 and was facilitated by WWF Nepal and the Department of National Parks \& Wildlife Conservation. Field survey, consultations and meetings were conducted to verify that management met the CA I TS criteria. Based on this evidence, a dossier was submitted to the CA I TS National Committee of Nepal for evaluation and feedback. The feedback provided by the committee was utilized to finalize the document, which was followed by an independent review of the CAITS process and outputs by an expert not involved in the CAITS assessment.

Despite the pressures that CNP faces, including the constant threat from poachers and high demands from tourism, the site has seen an increasingly effective management and protection regime put in place. Overall CNP demonstrated high conformity to CA I TS and, therefore, qualified to be a CA I TS Approved Site. The CA I TS National Committee of Nepal concluded that the dossier developed to indicate the achievement of the CAITS criteria shows that CNP is managed to the standards set out in CA I TS (Figure 4). In particular, CNP has a well-developed governance structure to include local people in management; active and supportive buffer zone communities; and benefit sharing is enshrined in law. In terms of community relationship management, as well as tiger monitoring and management, the site exceeds the CA I TS criteria (and thus highlights best practices). All the standards under the tourism, protection and habitat management pillars achieved the desired level of conformity, Standard Achieved. In a few areas of management not all the criteria were fully met (i.e., were assessed as Standard Mainly Achieved) but in these cases activities are underway to resolve outstanding issues and in no case do unfulfilled criteria represent a major impediment to tiger conservation. (Indeed, the Standard Mainly Achieved assessment can be a way of donors identifying priorities for investment.) For example, field posts needed to be improved through better provision and maintenance of clean drinking water (absent from some posts), solar power and infrastructure; however, there was insufficient budget available for these activities in the 2012-2016 management plan but fundraising was on-going at the time of the assessment and additional funding was secured after CA I TS Approval. When making the CA I TS Approved decision, the International Executive Committee requested the site to report on progress towards these field post improvements in 2016, particularly regarding safe drinking water at guard posts. WWF Nepal, as a focal agency facilitating CA I TS in Nepal worked with the National Park, Army and Best Paani Pvt Ltd. to provide bio-sand filtration systems, which were installed in 30 guard posts in September 2017, providing clean water for around 450 people. 


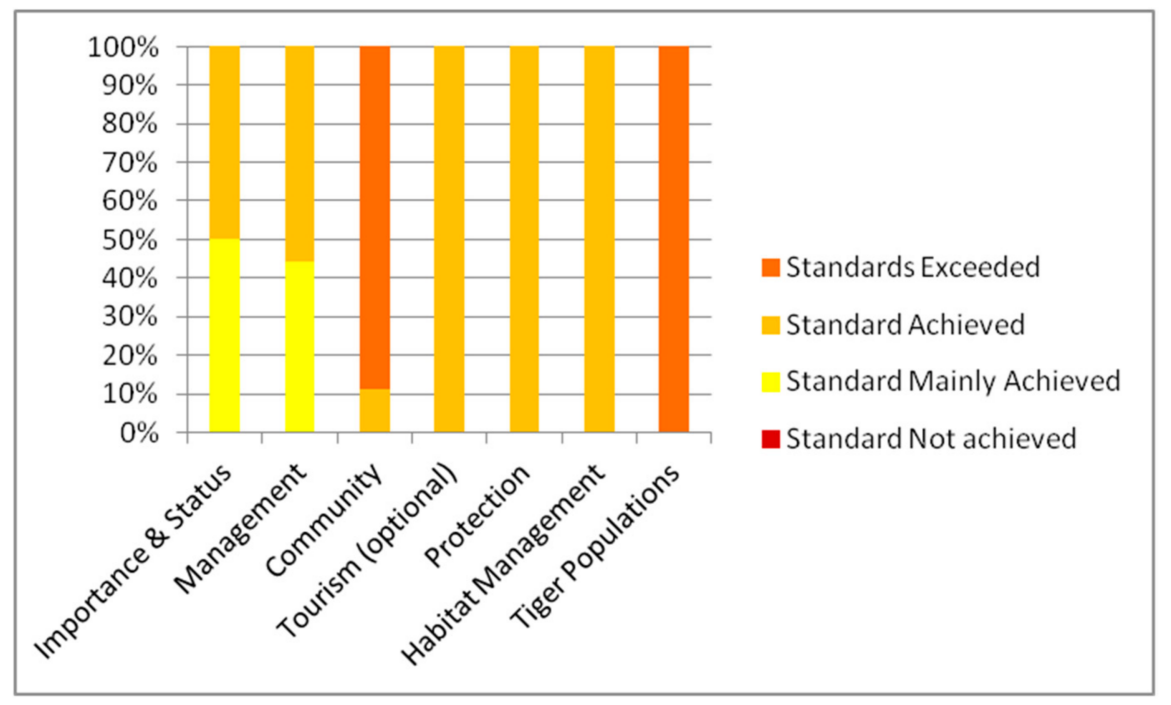

Figure 4. Overview of conformity of the 17 elements under seven pillars of CA I TS (see Figure 2) of CA I TS for Chitwan National Park.

The finalized dossier for CNP was submitted to the National Committee for its approval, which was achieved in October 2014. The Dossier was then passed to the CA I TS International Executive Committee for final approval. After discussion and some further information requirements from CNP (see above) the site was accredited as CA I TS Approved in January 2015. Since approval, Nepal has suffered a disastrous earthquake and flooding. After each disaster, updates on the impacts for tiger conservation in Chitwan were prepared by the protected area and National Committee. As the first site to receive CA I TS Approved status, Chitwan is also the first site to undertake the newly developed re-approval process, which is on-going (Conservation Assured, 2018a) [12].

Russia: Sikhote-Alin Nature Reserve (SANR) in Russia's Far East forms part of the easternmost habitat complex of tigers and has a unique combination of ecosystems. Tigers are found in low densities across a wide landscape, of which the SANR is only a small part. SANR had a tiger population of between 13-20 tigers in 2015 and is a source for populations for surrounding areas.

SANR was nominated as the first Russian site to take on CA I TS and the site was registered in December 2014. The field assessment began in 2015 and was aided by local and regional staff of WWF and the Wildlife Conservation Society. The National Committee (referred to in this case as the Jurisdictional Committee as it only representative of the small part of Russia where tigers are found) was established in March 2015. The assessment process went through several iterations after feedback from the Jurisdictional Committee, independent reviewers and CA I TS management team. After approval from the Jurisdictional Committee and International Executive Committee, CA I TS Approved status was conferred on SANR in July 2015.

SANR has a strong management system and a history of continuous monitoring of tigers, using the same protocols, going back 80 years. Annual plans for administration, finance, protection and infrastructure are linked to 3-year plans, and the management system has a robust auditing mechanism.

The CA I TS Dossier for SANR highlights both best practices and minor gaps in management practice (Figure 5). The results show that standards under the tiger population and habitat management pillar of CA I TS have exceedingly high levels of conformity, i.e., Standard Exceeded. All standards under the protection pillar have achieved the desired level of conformity, Standard Achieved. As in Nepal, in a few places where standards were assessed as Mainly Achieved, activities are underway to resolve outstanding issues and in no case does an unfulfilled criterion represent a major impediment to tiger conservation. For example, SANR has tourism potential. This could be a contributing factor to the local economy and could improve community livelihoods. At present, there is no tourism management 
plan in the reserve; however, the Amur Tiger Centre has a major goal to develop ecological tourism focused on the tiger in Russia and a project is being developed to raise interest in tigers amongst people living in European Russia, and thus to encourage tourism in the tiger range. SANR has now developed a plan to target ecological tourism aimed at the local community and which encourages volunteers and students to engage with management. Eco-trails have been built to give an experience of the wildlife and habitat along with an interpretation centre. An Ecotourism Club has also been setup locally to create more awareness about wildlife conservation and protection in Sikhote-Alin.

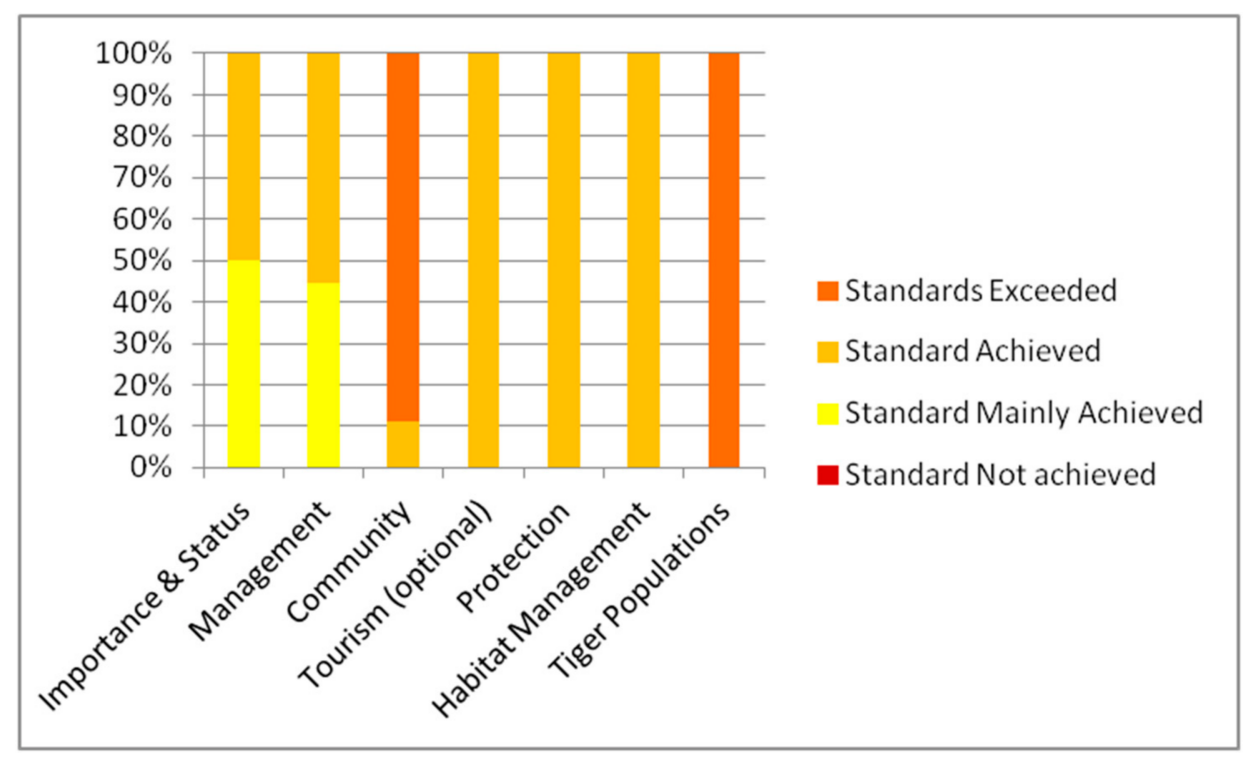

Figure 5. Overview of conformity of the 17 elements under seven pillars of CA I TS (see Figure 2) of CA I TS for Sikhote-Alin Nature Reserve.

India: Project Tiger was launched in 1973 in response to a serious decline in tiger numbers. Focused on the development and management of tiger reserves, the project has clearly had a beneficial impact on safeguarding wild tigers in the country (Johnsingh and Goyal, 2005) [27]. However, there are many important tiger populations and habitats outside tiger reserves, which have tended to receive less support and management focus. It was agreed that CA I TS would initially focus on these areas for its roll-out in India and the CA I TS National Committee in India drew up a preliminary list of nine forest reserves for the registration and implementation of CA I TS in September 2015.

Lansdowne Forest Division was the first area to become CA I TS Approved. Lansdowne is in the Pauri Garhwal district of Uttarakhand state in Northern India. It provides a crucial link between Rajaji and Corbett Tiger Reserves and is an important tiger and wildlife habitat in the western part of theTerai Arc Landscape. One-hundred-and-fifty-six tigers were camera trapped in March 2015 across 84 locations in Lansdowne; 23 were identified, of which 10 were females.

The CA I TS dossier was developed over 2016. After independent review and revision, the site was approved by the National Committee and reviewed by the International Executive Committee in May 2017. CA I TS Approved status was conferred after the submission of some additional material from the site.

The CA I TS pillars of community, protection, habitat management and tiger populations were all assessed as Standard Achieved (Figure 6). It was noted that a very competent protection strategy had been put in place over the last 7-8 years by the division manager who, amongst other things, had developed an intelligence-based protection system. Thus, although there is a lot of poaching pressure around the tiger reserves in the area, the Landsdowne tiger population is stable and has been growing over the last few years. Excellence (i.e., Standard Exceeded) was noted in both the importance and status and management pillars; however, some areas of management were also assessed as 
Standards Mainly Achieved, as staffing and funding gaps had been a problem at the site. However, the incorporation of Landsdowne into CA I TS leveraged further government funding to the site, allowing steps to fill staff capacity and infrastructure gaps. Tourism, which is a voluntary standard in CA I TS as not all tiger sites have tourists, has not been fully in developed in Landsdowne. However, there are plans to develop tourism further, to take pressure off the neighbouring tiger reserves and provide additional community benefits.

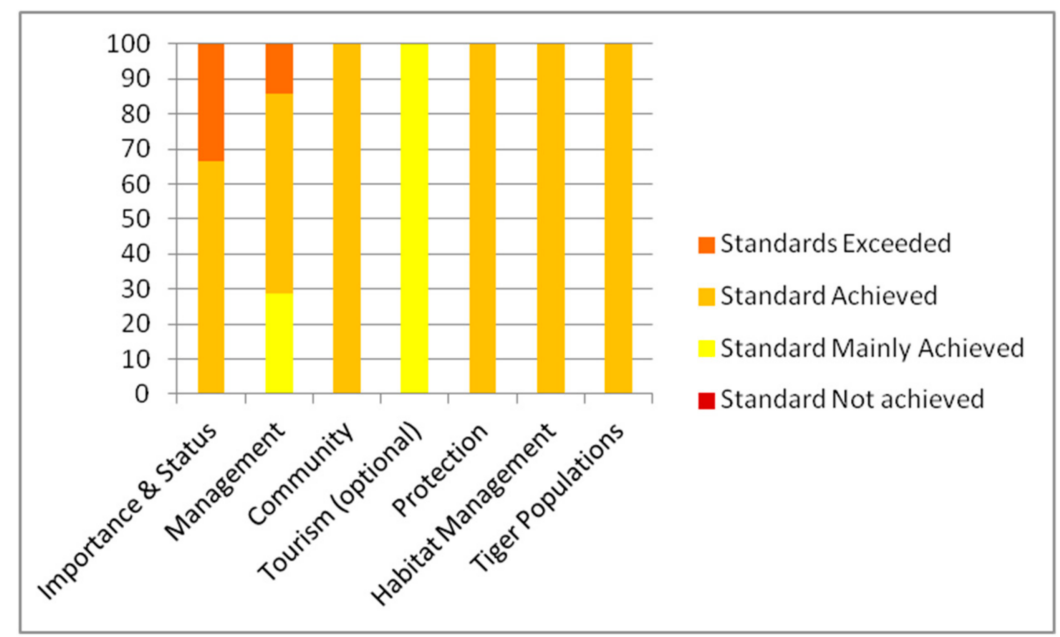

Figure 6. Overview of conformity of the 17 elements under seven pillars of CA I TS (see Figure 2) of CA I TS for Lansdowne Forest Division.

\section{Discussion: Lessons Learned from Five Years Developing the CA I TS Standards}

The development of CA I TS has been a multi-year project, involving many different actors across a range of countries. CAITS differs from many conventional environmental certification systems, because of its focus on capacity-building and the lack of an immediate market-based mechanism (such as a price premium for a certified product). As a result, there has been a steep learning curve amongst those involved. The following section summarises some of the lessons learned to date.

Although a number of existing organisations have been closely involved in the establishment of the system, particularly WWF, which has provided substantial logistical and financial support, CA I TS has from the start been an independent body. The assumption is that any single NGO, or any government body, will not have the independence, or at least will not be perceived as having the independence, to run an accreditation system. The result, successful to date, has been that governments, NGOs and international bodies such as UN agencies can all sit around the table as equal partners.

Regional governance is seen as critical to success, so that the CA I TS Council is chaired by a government representative (currently from Bhutan), which makes it easier for governments to engage directly in the process and has resulted in all 13 TRCs becoming actively engaged. This has already led, for example, to cross border exchanges between staff to share experiences and learn different approaches and techniques. It has also strengthened links with other international processes such as the Global Tiger Forum (GTF) and the St Petersburg Declaration. The existence of an active Support Group, including several NGOs, UNDP, GTF and IUCN, has resulted in enough funds and assistance to ensure that the process has continued. Furthermore, cooperation with the IUCN Green List, a global and more generally protected area accreditation system that has been under development during the same period (IUCN 2013) [25], has helped in the development of some of the processes.

However, implementation has taken longer than originally planned, in part because of the inevitable time-lags involved in running a participatory process. This is however problematic in light of the short time period remaining to achieve TX2 and the urgency of wider tiger conservation efforts. Perhaps unsurprisingly, it has proven easier to get active involvement from those countries already 
doing well in terms of tiger conservation than from those where capacity is low and effectiveness compromised, yet the latter are the primary target of the CA I TS initiative. The countries of Southeast Asia in particular have generally weaker tiger conservation systems (Conservation Assured, 2018) [1113] and at the same time have been less consistently engaged with CAITS. Further efforts, from governments, NGOs and donor agencies, remain important if CA I TS is not to be simply a reward for good management rather than also a tool for improving management.

While there has been good buy-in from TRCs, there are still challenges in getting CA I TS fully integrated with national systems and national Tiger Action Plans. Many of these had been completed by the time that the CAITS standard was in place and this, therefore, needs to be retrofitted into existing plans, if it is to become an integral part of everyday conservation and not a stand-alone project. Furthermore, the wide involvement of many stakeholders has made the system much stronger, but it also brings problems in terms of independent peer-review. Given the relatively small world of tiger conservation, most national experts suitable to reviews a site for CA I TS registration or approval will likely know many of the people involved in management, or themselves be involved in CA I TS. While there are policies in place to avoid direct conflict of interest, and the global International Executive Committee provides a check, this will inevitably remain an issue for any system of protected area verification, particularly in smaller countries.

Finally, the underlying philosophy of CA I TS driving increased management effectiveness is only going to work in the weaker TCAs if there is associated funding to build capacity. To date, this has been acquired on a fairly ad hoc basis, drawing on a surge of global support for tiger conservation. A longer term approach is needed and a business plan has been drawn up to this effect (Conservation Assured, 2018b) [13]. As well as setting out plans for the effective and efficient functioning of CA I TS at scale, the plan outlines an 'Advancement Programme' aimed at boosting the capacity of the TCAs to improve their management. This will require a very significant investment of funds either by the TRC governments or from donor sources. The plan suggests a new collective fund to provide support to the TCAs as the best method for financing these needs and the CA I TS Support Group has been discussing options for the development of such a fund (Conservation Assured, 2018b) [13].

\section{Conclusions-CA I TS and Into the Future}

The CA I TS vision is that wild tigers have spaces to live and breed safe from threat resulting in increased populations and recovery of range. To achieve this vision, CA I TS' two goals are that: (1) The adoption and implementation of CA I TS ensures tiger habitats are effectively conserved, well-managed and ecologically connected to maintain, secure and recover viable populations; and (2) CA I TS demonstrates and promotes best practice in protected area management in Asia. Whether achieving these goals will entail a long-term accreditation system, which will persist for decades, or whether CA I TS is more of a medium term capacity building tool whose usefulness will diminish over time is still open to question.

It is not simply the number of species that define the health of a landscape (Pollock et al., 2017) [28]. Tigers range across more than 50 habitats, with huge differences in elevation, temperature and ecosystem, so that CA I TS contributes to issues far broader than tiger conservation. Furthermore, in the context of severe declines in many flagship species (Butchart et al., 2010) [29], including particularly those targeted by the wildlife trade such as rhinoceros, elephant and pangolin, the CA I TS methodology could be modified for other species reliant on site-based conservation. The five conservation pillars of CA I TS are directly transferable; specific standards would need to be developed in accordance with other species' biology, protection and habitat management. Discussions are ongoing on developing Conservation Assured standards for several species groups such as rhinos, pangolins, river dolphins and some plants. Integrating the Conservation Assured philosophy into wider conservation discourse is the next priority in the development of this approach.

Author Contributions: Writing-Original Draft Preparation: M.K.S.P., N.D. and S.S.; Writing-Review \& Editing: M.B. (Michael Baltzer), B.L., S.R., M.B. (Michael Belecky), R.G. and S.P.Y. 
Funding: This research received no external funding.

Acknowledgments: We would like to thank all the Tiger Range Governments (TRCs) and the CA I TS Partnership for their support in rolling out CA I TS. We are also grateful to all those sitting on the National Committees in Nepal and India and Jurisdictional Committees in Russia, site managers, reviewers and the CA I TS International Executive Committee members who have invested their time to work on the assessments and review of the three CA I TS Approved sites presented in the paper. Special thanks to Dmitry Gorshkov, Yury Darman, Sergey Aramilev and Dale Miquelle from Russia; DVS Khati, Djananjay Mohan and Nitish Kumar from India; Bishwa Nath Oli, Maheshwar Dkahal, Diwakar Chapagain, Shyam Bajimaya and all the teams in WWF Russia, India and Nepal for facilitating the CA I TS implementation and site assessments. We are thankful to the State Forest Department of Uttarakhand, for being the first State to roll out CA I TS in India. The CA I TS Support Group has been a strong force for driving the CA I TS globally, we are thankful to all of them. The GTF has also played a very strong role in the adoption of CA I TS across TRCs and advocating the benefits of CA I TS for long-term tiger conservation, we thank them for their support.

Conflicts of Interest: The authors declare no conflict of interest.

\section{References}

1. Wolf, C.; Ripple, W.J. Range contractions of the world's large carnivores. R. Soc. Open Sci. 2017, 4, 170052. [CrossRef] [PubMed]

2. Walston, J.; Robinson, J.G.; Bennett, E.L.; Breitenmoser, U.; Da Fonseca, G.A.B.; Goodrich, J.; Gumal, M.; Hunter, L.; Johnson, A.; Karanth, K.U.; et al. Bringing the tiger back from the brink-The six per cent solution. PLoS Biol. 2010, 8, e1000485. [CrossRef] [PubMed]

3. WWF. Priority Species. 2015. Available online: http:/ / tigers.panda.org/tiger-facts/ (accessed on 27 July 2018).

4. Stoner, S.S.; Pervushina, N. Reduced to Skin and Bones Revisited: An Updated Analysis of Tiger Seizures from 12 Tiger Range Countries (2000-2012); Traffic: Kuala Lumpur, Malaysia, 2013.

5. Damania, R.; Seidensticker, S.; Whitten, T.; Sethi, G.; MacKinnon, K.; Kiss, A.; Kushlin, A. A Future for Wild Tigers; World Bank: Washington, DC, USA, 2008.

6. Global Tiger Initiative (GTI). The St. Petersburg Declaration on Tiger Conservation. 2010. Available online: cmsdata.iucn.org/downloads/st_petersburg_declaration_english.pdf (accessed on 9 January 2018).

7. Roy, S.; Vie, J.C.; Gelsi, T. The Integrated Tiger Habitat Conservation Programme-Progress to date. Cat News 2016, 63, 35-36.

8. Geldmann, J.; Coad, L.; Barnes, M.; Craigie, I.D.; Woodley, S.; Balmford, A.; Brooks, T.M.; Hockings, M.; Knights, K.; Mascia, M.B.; et al. A global analysis of management capacity and ecological outcomes in protected areas. Conserv. Lett. 2018, 11, e12434. [CrossRef]

9. Leverington, F.; Costa, L.L.; Pavese, H.; Lisle, A.; Hockings, M. A Global Analysis of Protected Area Management Effectiveness. Environ. Manag. 2010, 46, 685-698. [CrossRef] [PubMed]

10. Brun, C.; Cook, A.R.; Lee, J.S.H.; Wich, S.A.; Pin Koh, L.; Carrasco, L.R. Analysis of deforestation and protected area effectiveness in Indonesia: A comparison of Bayesian spatial models. Glob. Environ. Chang. 2015, 31, 285-295. [CrossRef]

11. Conservation Assured. Safe Havens for Wild Tigers: A Rapid Assessment of Management Effectiveness against the Conservation Assured Tiger Standards; Conservation Assured: Singapore, 2018.

12. Conservation Assured. CAITS Manual Version 2.0; Conservation Assured: Singapore, 2018.

13. Conservation Assured. Conservation AssuredI Tiger Standards 2018-2022; Business Plan; Conservation Assured: Singapore, 2018.

14. Hockings, M.; Stolton, S.; Leverington, F.; Dudley, N.; Courrau, J. Evaluating Effectiveness: A Framework for Assessing Management Effectiveness of Protected Areas, 2nd ed.; IUCN: Gland, Switzerland; Cambridge, UK, 2006. Available online: https:/ / portals.iucn.org/library/efiles/documents/pag-014.pdf (accessed on 27 July 2018).

15. Coad, L.; Leverington, F.; Burgess, N.D.; Cuadros, I.C.; Geldmann, J.; Mathews, T.R.; Mee, J.; Nolte, C.; Stoll-Kleemann, S.; Vansteelant, N. Progress towards the CBD protected area management effectiveness targets. PARKS 2013, 19, 13-24. [CrossRef]

16. Mathur, V.B.; Gopal, R.; Yadav, S.P.; Negi, H.S. Management Effectiveness Evaluation of Tiger Reserves; Technical Manual No. WII-NTCA/01/2010 pp 21; Revised and Updated Version; WII-NTCA/01/2014 pp 25; National Tiger Conservation Authority and Wildlife Institute of India: New Dehli, India, 2014.

17. Convention on Biological Diversity (CBD). Programme of Work on Protected Areas (UNEP/CBD/COP/7/21); Secretariat of the Convention on Biological Diversity: Montreal, QC, Canada, 2004. 
18. Polasky, S.; Tallis, H.; Reyes, B. Setting the bar: Standards for ecosystem services. Proc. Nat. Acad. Sci. USA 2015, 112, 7356-7361. [CrossRef] [PubMed]

19. Ferraro, P.J.; Pattanayak, S.K. Money for nothing? A call for empirical evaluation of biodiversity conservation investments. PLoS Biol. 2006, 4, e105. [CrossRef] [PubMed]

20. McCarthy, D.P.; Donald, P.F.; Scharlemann, J.P.W.; Buchanan, G.M.; Balmford, A.; Green, J.M.H.; Bennun, L.A.; Burgess, N.D.; Fishpool, L.D.; Garnett, S.T.; et al. Financial costs of meeting global biodiversity conservation targets: Current spending and unmet needs. Science 2012, 338, 946-949. [CrossRef] [PubMed]

21. Bennett, J.R.; Maloney, R.; Possingham, H.P. Biodiversity gains from efficient use of private sponsorship for flagship species conservation. Proc. R. Soc. B Biol. Sci. 2015, 282, 1-7. [CrossRef] [PubMed]

22. ISEAL. Principles for Credible and Effective Sustainability Standards; ISEAL: London, UK, 2013.

23. Gray, T.N.E.; Crouthers, R.; Ramesh, K.; Vattakaven, J.; Borah, J.; Pasha, M.K.S.; Lim, T.; Phan, C.; Singh, R.; Long, B.; et al. A framework for a ssessing readiness for tiger Panthera tigris reintroduction: A case study from eastern Cambodia. Biodivers. Conserv. 2017, 26, 2383-2399. [CrossRef]

24. Conservation Assured. Conservation Assured I Tiger Standards: A Multifunctional Protected Area Management Tool to Aid Implementation of International Conventions, Multilateral Treaties, Global Initiatives E National Action; Conservation Assured: Petaling Jaya, Malaysia, 2014.

25. IUCN. The IUCN Red List of Threatened Species. IUCN Green List Boosts Partnership with a New Tiger Conservation Initiative at the Asia Parks Congress. 2013. Available online: http:/ / www.iucnredlist.org/news/iucn-green-list-boosts-partnership-with-a-new-tiger-conservationinitiative-at-the-asia-parks-congress (accessed on 27 July 2018).

26. CITES. Convention on International Trade in Endangered Species of Wild Fauna and Flora (CITES). In Proceedings of the Seventeenth Meeting of the Conference of the Parties, Johannesburg, South Africa, 24 September-5 October 2016; CoP17 Doc. 60.1. Available online: https:/ / cites.org/sites/default/files/eng/ cop/17/WorkingDocs/E-CoP17-60-01.pdf (accessed on 27 July 2018).

27. Johnsingh, A.J.T.; Goyal, S.P. Tiger Conservation in India: The Past, Present and the Future. Indian For. 2005, 131, 1279-1296.

28. Pollock, L.J.; Thuiller, W.; Jetz, W. Large conservation gains possible for global biodiversity facets. Nature 2017, 546, 141-157. [CrossRef] [PubMed]

29. Butchart, S.H.M.; Walpole, M.; Collen, B.; Van Strein, A.; Scharlemann, J.P.W.; Almond, R.E.A.; Baillie, J.E.M.; Bomhard, B.; Brown1, C.; Bruno, J. Global biodiversity: Indicators of recent declines. Science 2010, 328, 1164-1168. [CrossRef] [PubMed] 